\title{
Improving Access to Hands-On STEM Education using a Mobile Laboratory
}

\author{
William H. Roden ${ }^{1}$, Rebecca A. Howsmon², Rebecca A. Carter ${ }^{1}$, Mark Ruffo ${ }^{3}$, and Amanda L. Jones ${ }^{1}$
}

${ }^{1}$ Science Education Department, Seattle Children's Research Institute, Seattle, WA; ${ }^{2} T E A L S$, Redmond, WA; ${ }^{2}$ Landesa Rural Development Institute, Seattle, WA DOI: 10.15695/jso.v1i2.4550s

Keywords: Mobile Science Laboratory, Primary Education, Outreach, STEM Education, STEM Careers, Under-served Urban and Rural Communities

\begin{abstract}
Schools often have limited resources to devote to science education, which can impact student interest in and preparedness for careers in STEM. Seattle Children's Research Institute created the Science Adventure Lab, a mobile laboratory program, to support and enrich science education at low-resource schools and stimulate interest in science and pursuing a career in STEM. The mobile laboratory provides students with the unique opportunity to fully immerse themselves in authentic, hands-on science learning with scientists. This limits the burden on school resources and reduces disruptions to daily schedules since students do not leave their schools. These positive science experiences at an early age allow students to learn important science concepts and have the potential to significantly impact students' interest in pursuing STEM careers. In this report we describe our mobile laboratory, operating model, and curriculum, as well as the positive impacts, strengths, and challenges of the approach as a resource for other groups who may wish to use a similar strategy for STEM education outreach.
\end{abstract}

\section{INTRODUCTION}

High-quality science education has never been more critical since nine of the ten fastest growing occupations in the United States now require significant math or science training, and employers in both traditional and non-traditional STEM fields are seeking workers who are already equipped with STEM knowledge (Lacey and Wright, 2009; Pellegrino and Hilton, 2012; Lennon, 2014; Adams, 2015). Furthermore, in our increasingly technological and scientific society, an understanding of the nature of science and scientific inquiry is critical for all, not just those in the STEM workforce (National Research Council, 2013). While some progress in science education has been made in the United States, according to the 2015 National Assessment of Educational Progress (NAEP) only one third of students have the skills they will need to be adequately prepared for college-level science classes and for a career in STEM (U.S. Department of Education, 2016).

There is a substantial body of research demonstrating that active engagement with hands-on learning that includes authentic scientific tools is the most effective way for students to learn and retain science knowledge (Sivan et al., 2000; Knox et al., 2003; Markowitz, 2004; Bell et al., 2009). De- spite this, many schools still lack access to equipment, resources, and trained personnel. As part of Seattle Children's commitment to promoting the health and wellbeing of children, an outreach program was established in 2008 with the following goals:

- Supporting science education in schools across Washington state by partnering with teachers to deliver innovative educational experiences in an authentic laboratory setting

- Providing access to authentic scientific and medical equipment to low-resource urban and rural schools

- Improving awareness of careers in science, healthcare, and other STEM fields among students from groups traditionally underrepresented in STEM

- Promoting healthy behaviors by providing educational activities that address key topics in child health

After reviewing the science education outreach landscape, we determined that a mobile laboratory was the ideal platform for meeting our goals and generating enthusiasm for careers in STEM and healthcare in Washington. Hence, the Science Adventure Lab, Seattle Children's Research Institute's (SCRI) mobile laboratory program, was launched in 2009. The focus of the outreach was on students in elemen- 
tary and middle school since they are least likely to have access to laboratory experiences and authentic equipment. Also, research has demonstrated that positive science experiences in elementary years can establish a strong foundation of interest and knowledge in the sciences that benefits students' academic performance and significantly impacts their interest in pursuing a STEM career (Swift and Watkins, 2004; Tai et al., 2006). We also sought to help address the inequity of access to high-quality science education in low-resource schools and low-income communities, which is known to contribute to the underrepresentation of minority groups in the STEM fields (Chen and Weko, 2009; Committee on Underrepresented Groups and the Expansion of the Science and Engineering Workforce Pipeline, 2011; Banilower et al., 2013; Committee on STEM Education, 2013). Thus, the program was designed to prioritize visiting Title I-eligible schools, rural schools, and schools with high percentages of students receiving free or reduced price lunch (FRPL).

In this report we describe our mobile lab, operating model and curriculum, and the associated positive impacts, challenges, and limitations as a resource for other groups who may wish to use a similar strategy for STEM education outreach in their communities.

\section{METHODS}

Program Description. The Science Adventure Lab is one of the programs operated by the Science Education Department at SCRI located in Seattle, Washington. The Science Adventure Lab program is primarily focused on students from underserved populations and with backgrounds traditionally underrepresented in STEM fields. The program was intended to provide science education outreach without placing a financial burden on the school; thus, Science Adventure Lab visits are provided at no charge to qualifying schools. The program was designed for students in grades four through eight. The lower grade level limit was set at grade four due to the need for students to be able to safely reach standard height lab benches and effectively use the laboratory equipment.

Schools requested visits through a competitive application process. The program capacity was determined by the number of full school days each academic year. Requests for visits were prioritized based on the following metrics: 1) percentage of students eligible for FRPL; 2) eligibility for Title I funding; and 3) location. Priority for visits was given to schools with more than $50 \%$ of students receiving FRPL, Title I-eligible schools, and rural schools. FRPL data were obtained from the State of Washington Office of Superintendent of Public Instruction (OSPI). Title I eligibility and geographical classification for each school was obtained from the National Center for Education Statistics (NCES).
Schools were required to provide accessible off-street parking for the mobile lab in order to be eligible for a visit. The school visits were scheduled in the spring for the following school year (6-12 months in advance). Visits were one to four days in duration depending on the number of classes that participated. Multi-day visits occurred more frequently at urban schools since they had a larger student population than rural schools. The Science Adventure Lab typically spent three or four days per week visiting schools, with one or two days reserved for preparing the materials for the school visits as well as other administrative functions.

In the first year of operation, information about the program was distributed through the Educational Service Districts (ESDs) in the main population centers of the state. This resulted in greater demand than could be accommodated, so promotion was scaled back in subsequent years. Each year, at least $25 \%$ of the school visits were reserved for schools that had not previously received a Science Adventure Lab visit. Schools selected which grade level participated in the visits and whether the same grade level participated in the following years. As a result, some students had more than one experience, while others had only a single experience.

The Mobile Laboratory. The Science Adventure Lab was custom-built by Farber Specialty Vehicles (Reynoldsburg, $\mathrm{OH}$ ) in 2009. It is a 45-foot, coach-style vehicle with a diesel engine in the rear (Figure 1a). In choosing a vehicle type, we considered the urban nature of SCRI's downtown campus and the locations of eligible schools, which often had limited accessibility and parking. The vehicle and interior finishes were designed jointly by engineers from Farber Specialty Vehicles, the program team from SCRI, and architects from NBBJ, which is the same firm that designed SCRI (Figure 1b). This collaborative design process resulted in a mobile lab that reproduced a functional, authentic research laboratory. The mobile lab supports a maximum class size of 30 . Students work in groups at six laboratory bench "stations," and instructors use a fully integrated audio/visual system to supplement the verbal instruction with multimedia presentations and demonstrations.

Interior power is provided by a $25 \mathrm{~kW}$ liquid-cooled diesel generator mounted under the vehicle deck in a stainless steel compartment insulated with high-density, sound-absorbing foam. Four slide-out extension rooms increase the useable interior space to a total of 454 sq. ft. The Science Adventure Lab also has a built-in wheelchair lift, which complies with the Americans with Disabilities Act (ADA) for accessibility. The vehicle weighs 38,000 pounds, classifying it as a commercial vehicle and requiring the driver to have a class B Commercial Driver's License. The Science Adventure Lab has seating for the driver and two passengers. A support vehicle is used when additional instructors are needed or an extended trip is required. 



Figure 1. (a) The Science Adventure Lab (exterior). (b) The Science Adventure Lab (interior). (c) Students explore chemistry during Seeking the Sugar Solution. (d) Students isolate DNA during Where is Your DNA? (e) Students measure their peak flow rate during Catch Your Breath. (f) Students measure their temperature during Vital Signs. (g) Students explore brain anatomy during Sense, Think, Move. (h) Students perform gel electrophoresis during Stop the Outbreak. 
Curriculum. Instruction in the mobile lab is provided by trained scientists with backgrounds in diverse scientific fields and board-certified educators. The lessons, referred to as curriculum modules, were developed de novo by program staff with input from scientists, educators, and other mobile laboratory programs using the 5E Instructional Model (Bybee et al., 2006), or modified from an existing commercially available kit. The modules are grade-level appropriate with basic versions available for students in grades four through six that are 60 minutes in duration and advanced versions available for students in grades seven and eight that are 75 or 90 minutes in duration. The modules are aligned to the Next Generation Science Standards (NGSS). Several of the modules also address key aspects of pediatric health such as asthma, nutrition and diabetes, head injuries, and infectious diseases.

All modules require the use of authentic research-grade scientific and medical equipment, computers and other technology, and include opportunities for students to analyze data and perform mathematical calculations. The overarching intent is for students to begin to develop the laboratory skills and knowledge required to conduct an experiment, test hypotheses, and build confidence in their ability to be successful in the sciences. All instructors receive extensive training to ensure fidelity of delivery of the modules. All of the activities are optimized for use in mobile laboratories, which includes considering limited storage of the mobile lab; the use of non-hazardous materials that can be stored, transported, and disposed of in a moving vehicle; limited space for students onboard; and time constraints associated with completing the experiment in a single class period.

Teachers select which module they want delivered based on alignment with ongoing classroom curricula. There are three components to each curriculum module. First, during the pre-lab activities, which are completed prior to the Science Adventure Lab visit, students watch a video on laboratory safety and an animated video that introduces key terms and concepts. The students also complete an activity in the classroom that is led by their classroom teacher. The prelab activities can be completed in less than one class period. Second, onboard the Science Adventure Lab, the curriculum module is led by Science Adventure Lab instructors and lasts 60 to 90 minutes, depending on which lesson is being taught. Third, after the visit, teachers are expected to complete an additional post-lab activity in the classroom that extends and reinforces the learning.

Permission slips signed by a parent or guardian are required for students to participate in the activities onboard the mobile lab. The permission slip describes the activity that the students will do, expectations for appropriate behavior and attire, and includes consent to collect photographs, which is optional. The permission slips, materials for the pre-lab activity, and videos on DVD are shipped to the teachers at least two weeks in advance of the visit. The modules and relevant equipment are described below. Figures 1c-h show students performing each of the curriculum modules onboard the mobile lab.

Modules. Seeking the Sugar Solution. In this module created by the program team, students conduct a chemistry experiment to determine how much sugar is in a simulated beverage by using Benedict's reagent to produce a visible red precipitate in proportion to the amount of sugar. Students compare the color change to that of standards containing known concentrations of glucose. Students learn nutrition and health facts that support making healthy decisions about the beverages they consume and reflect on their own sugar consumption. This module uses transfer pipettes or micropipettes, vortex mixers, heat blocks, and Benedict's reagent. The advanced version, designed for students in grades seven and eight, includes additional pipetting and aliquoting of materials.

Where is Your DNA? In this adaptation of the Bio-Rad Genes in a Bottle kit, students isolate DNA from their own cheek epithelial cells using a standard DNA isolation protocol that includes lysis, separation, and precipitation. Students learn about the properties and function of DNA and that isolating DNA is the first step in advanced biotechnology applications such as cloning, DNA sequencing, and DNA fingerprinting. The extended, advanced version of the module includes microscopic examination of Safranin-stained check cells and a discussion of the components of the cells.

Catch Your Breath: Exploring Respiratory Function and Asthma. In this module, students learn about the basic anatomy and physiology of the respiratory system, how conditions such as asthma affect the respiratory system, and how scientists and healthcare professionals assess respiratory functions. Students measure the oxygen saturation level in their blood using standard pulse oximeters, their peak flow rate using a peak flow meter, and their lung volume using a Vernier spirometer. A PneuFlo ${ }^{\circledR}$ Parabolic Resistor (Rp50) is then attached to the spirometer so students can experience the sensation of breathing through an asthmatic airway. The purpose of this activity using the resistor is to build upon students' understanding of asthma's effects and help generate empathy for people who have asthma. The extended version of the module includes the use of the BioQuest ${ }^{\circledR}$ healthy and simulated smoker's lungs demonstration kit. Students learn more about lung anatomy and physiology and discuss the effects of smoking and lung cancer.

Vital Signs: Monitoring Our Body's Systems. In this module, students learn about body systems and how vital signs are measured and used to reveal and monitor medical problems. Students measure their heart rate and blood pressure using a standard wrist blood pressure cuff, their respiratory rate using a Vernier spirometer, and their temperature using 
an Exergen infrared scanning temporal thermometer. The extended version includes an activity with a Laerdal SimJunior ${ }^{\circledR}$ patient simulator. Students learn how patient simulators can be used to train medical professionals to respond to emergencies by participating in a scenario that simulates an anaphylactic reaction to peanuts. Students monitor the simulator's vital signs, assess the situation, and follow a decision chart to decide on the appropriate response of administering epinephrine.

Sense, Think, Move: Exploring Brain Functions. In this module, students learn about the nervous system and how the brain functions as the primary control center for the body. There are three activities that demonstrate how the brain controls sensing, thinking, and moving. In the first activity, students learn about their senses and identify five common odors as a demonstration of olfactory processing. In the second activity, students learn about comparative brain anatomy while identifying five animal brains embedded in Lucite ${ }^{\circledR}$ (Lucite Treasures). In the third activity, students record the electrical activity of their forearm muscles during simple movements using a Vernier electromyograph. In the extended version, students learn more about the structure and function of the brain by examining cow brains.

Stop the Outbreak. In this module designed for students in grades seven and eight, students participate in an investigation to determine which food is responsible for a fictional foodborne illness outbreak at a food festival. The Science Education team adapted the Bio-Rad Forensic DNA kit to create this module. The module includes the use of micropipettes, mini-centrifuges, electrophoresis apparatus, and a UV imaging system.

Data Collection. Data are collected in real time onboard the mobile lab using a Qwizdom remote audience response system. Multiple choice questions are embedded in the PowerPoint presentations used for each module. All responses are anonymous. Data are compiled and results are presented in real time as a visual chart by the accompanying Qwizdom Connect software suite that works with PowerPoint. Individual student data are exported as a delimited spreadsheet file for further analysis. The questions measure content knowledge and comprehension, interest in STEM careers, and engagement in learning science while the students are onboard the mobile lab. No pre-test data are collected.

During the developmental stages of the program, participating teachers were asked to complete online surveys about the value and suitability of the content, any follow up activities they did, as well as their satisfaction with general program logistics such as communication and pre-visit materials.

Ethics Statement. All program activities and materials were reviewed by the Institutional Review Board at SCRI and qualified as an exempt study.

\section{Results}

Participants. For the 2009/10 through 2016/17 school years, the Science Adventure Lab team conducted 668 school visits, presenting curriculum modules to 55,540 students at 165 unique schools throughout Washington state (Table 1). Sixty-two percent of the students who participated were in grades four or five, $27.6 \%$ were in grades six through eight, and $10.4 \%$ were in multi-grade classrooms (could not determine the grade level of individual students). Some students in grade six attended a K-6 elementary school, while others attended a middle school. Seventy-two percent of the visits were to elementary schools (K-5 or K-6) and $20.2 \%$ were to middle schools. The mobile lab also visited a small number of K-8 and K-12 schools.

The mobile lab visited schools in all nine of the ESDs in Washington. The majority of schools visited $(71.9 \%)$ were in cities and suburban locations; $28.1 \%$ of schools visited were in rural locations and towns with populations less than 50,000 . Ten percent of the population of Washington state lives in rural areas (United States Department of Agriculture Economic Research Service, 2018), suggesting that the program is meeting the objective of providing outreach to rural communities. The Science Adventure Lab visited schools in 69 different cities or towns in 22 different counties across

Table 1. Student and school characteristics for Science Adventure Lab visits (2009/10-2016/17).

\begin{tabular}{ccccc}
\hline & Number of students & Number of schools & Rural & FRPL $^{1}$ \\
\hline $\begin{array}{c}\text { Science Adventure } \\
\text { Lab program }\end{array}$ & $\begin{array}{c}55540 \\
\text { (range } 6,294-7,773 / \\
\text { year) }\end{array}$ & $\begin{array}{c}165 \text { schools } \\
668 \text { visits }\end{array}$ & $\begin{array}{c}28.1 \% \text { of schools } \\
(18.3 \% \text { of visits })\end{array}$ & $60.00 \%$ \\
WA state & $1,102,579^{1}$ & $2,436^{2}$ & $10 \% \%^{3}$ & $44.40 \%$ \\
\hline
\end{tabular}

\footnotetext{
${ }^{I}$ Data obtained from OSPI for 2016/17

${ }^{2}$ Data obtained from NCES for 2016/17

3 Data obtained from NCES for 2015/16; 2016/17 data not available

${ }^{4}$ Self-reported by schools receiving visits
} 
Washington. The majority of visits were to schools located within a one-hour drive from downtown Seattle where SCRI is located. We also visited schools in other parts of the state including rural coastal areas and central and eastern Washington. School visits to these regions were scheduled in blocks for efficiency.

According to the OSPI, $60 \%$ of students at schools visited by the Science Adventure Lab received FRPL (Table 1). The average for Washington state schools in 2016/17 was 44.4\% of students receiving FRPL. Similarly, $90.6 \%$ of schools visited by the Science Adventure Lab self-identified as Title I. The average for the state of Washington in 2015/16 was $64.9 \%$ (Table 1). These data suggest that the program is meeting the goal of prioritizing schools with high percentages of students receiving FRPL and Title I-eligible schools.

Based on the demographic data for schools visited by the Science Adventure Lab, the diversity of the students participating exceeded that of the general population of public school students in the state. Of note, from 2009/10 through 2016/17, the schools visited had approximately twice as many students identifying as American Indian, Alaskan Native, Black, Native Hawaiian, or Pacific Islander compared to state averages. The populations at the schools visited also identified as approximately $40.8 \%$ white, compared to $55.2 \%$ across the state (Figure 2). These data suggest that the program is reaching those students who have been shown to be underrepresented in the STEM fields.

Comprehension of Subject Matter. Questions were embedded in the PowerPoint presentations to monitor comprehension of the instruction and content knowledge while the students were onboard. The goal was that students would correctly answer $70 \%$ of the questions, suggesting that they

a)

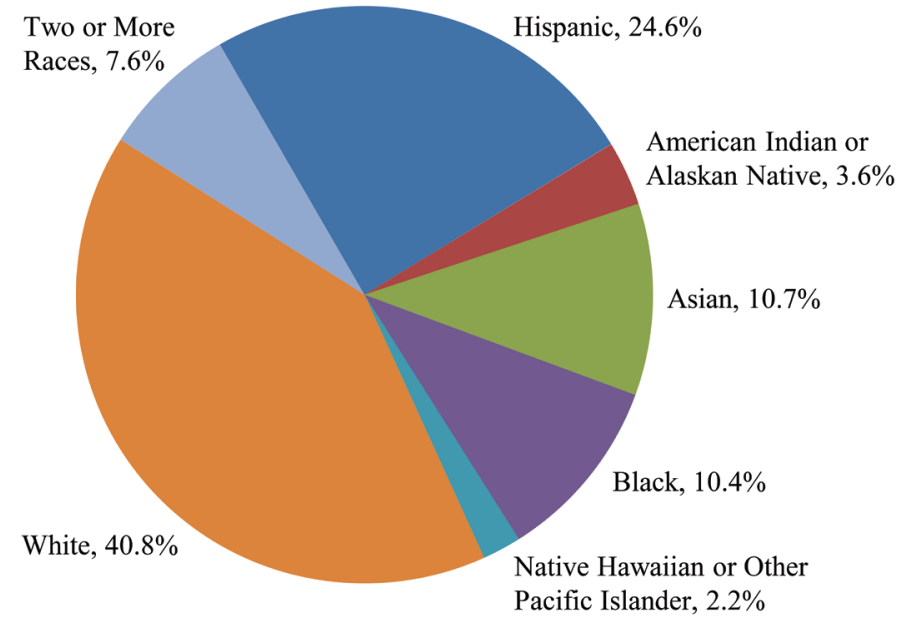

comprehended the majority of the content. If the percent of correct responses was significantly above or below $70 \%$, the complexity of the instruction was adjusted and/or the questions were modified. Each curriculum module presentation contained three to seven questions.

As seen in Table 2, elementary school students correctly answered on average $71.4 \%$ of the questions (range $65.0 \%$ $85.4 \%$ ) across all modules. Middle school students correctly answered an average of $70.0 \%$ of the questions across all modules (range 63.4\%-85.8\%). These data represent a snapshot of students' comprehension while they were onboard. Gains in knowledge were not measured, as no pre-test data were collected.

Table 2 also shows the number of students who answered the questions. The three most popular modules chosen by elementary school teachers were Seeking the Sugar Solution; Where is Your DNA?; and Sense, Think, Move. Seeking the Sugar Solution, Stop the Outbreak, and Where is Your DNA? were the most popular modules selected by middle school teachers. The questions were phased in over time, so not all students completing a module answered the questions.

Interest and Engagement. The limited duration of exposure on a mobile lab is a well-known challenge for rigorously measuring the impact of the experience (Jones and Stapleton, 2017). Students completing modules onboard the Science Adventure Lab were asked a multiple choice question about their interest in pursuing a career in STEM and a question about their general perspective on learning science. Interest and engagement questions were included whenever possible in modules taught between 2011 and 2017. One of the response choices for the question about students' interest in pursuing a career in STEM was intended to serve

b)

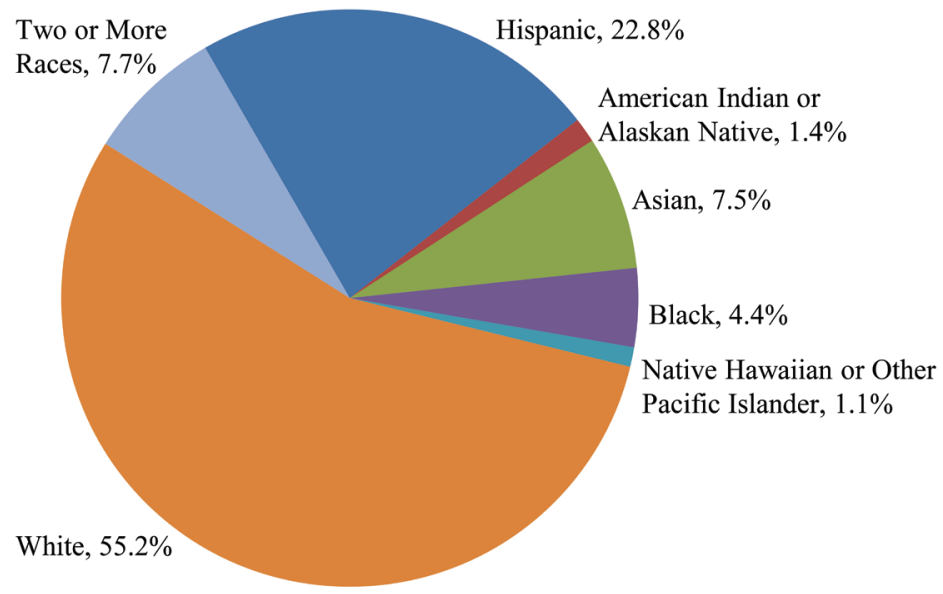

Figure 2. Race/ethnicity averages for students at schools (a) visited by the Science Adventure Lab from 2009/10-2016/17 ( $=55,450$ ) and (b) across WA state in 2016/17 $(\mathrm{n}=1,102,579)$. 
as a proxy for measuring the impact of the experience. A subset of the students participating (14.2\%) selected "Not before today, but now I do", suggesting that participating in the program had positively impacted their interest in pursuing a career in STEM, at least in the short term. The other response choices included "I have always wanted to" which was selected by $34.1 \%$ of respondents and "Maybe" which was selected by $33 \%$ of respondents. We were encouraged by the fact that only $18.7 \%$ of students selected "Not really". These data suggest that the majority of students are interested, or would at least consider pursuing a career in STEM. All response choices were presented to students in a positive tone. For example, when reading the response choice "Not really", instructors added "Because I have another career in mind such as writer, musician, lawyer, etc."

We also asked students for their general perspective on learning science. As seen in Figure 3, the percentage of students stating that science is their favorite subject is highest for students in grade four, and that percentage decreases as grade level rises. This is mirrored by the increase in the percentage of students stating that they do not really like science as grade level rises. Our observations are consistent with published literature describing a decline in interest in science as students enter middle school (Potvin and Hasni, 2014).

Teacher Feedback. Between 2011 and 2014, 201 teachers completed an online survey following the visit. Regardless of module, the majority of teachers $(89.4 \%)$ found the content to be appropriately challenging for their students. When considering whether the activity helped students learn important content and meet state science standards, $82.3 \%$ of teachers rated the activities four or five on a five-point Likert scale (with five being the most positive). As a measure of student engagement, we also asked teachers to report how often they observed their students discussing their experience on the Science Adventure Lab following the visit. Overall, 66.8\% of teachers reported that their students discussed their experience at least once or twice in the week following the visit, with $27.1 \%$ of teachers reporting that their students discussed their experience three or more times. Many of these discussions appear to be student-initiated, considering only $40 \%$ of reporting teachers completed a follow-up activity after the visit. Over time, teacher feedback stabilized and became repetitive, so the online surveys were discontinued, and teachers were encouraged to provide direct feedback to the program team.

\section{DISCUSSION AND CONCLUSIONS}

The characteristics of the schools visited by the Science Adventure Lab indicate that the program is meeting the objective of providing outreach to low-resource, Title I-eligible schools with high populations of students receiving FRPL. Schools visited by the Science Adventure Lab were also more diverse than the average for the state. While the Science Adventure Lab has not yet visited every Washington state school that qualifies for the program, schools in 69 different cities or towns in 22 different counties and all nine ESDs across the state of Washington have received one or more visits over the past eight years, suggesting that the program is meeting the goal of providing outreach to schools across the state. The factors limiting capacity are the number of teachable days in a school year and the fact that, at present, the program only operates a single mobile lab.

Comprehension data collected from student participants

Table 2. Student responses for comprehension questions by school level and module (2009/10-2016/17); n=number of respondents.

\begin{tabular}{ccc} 
Module & $\begin{array}{c}\text { Average percent correct for elementary } \\
\text { school students }{ }^{1}\end{array}$ & $\begin{array}{c}\text { Average percent correct for middle school } \\
\text { students }\end{array}$ \\
\hline Basic Where is Your DNA? & $65.0(\mathrm{n}=8,185)$ & $65.4(\mathrm{n}=485)$ \\
Basic Seeking the Sugar Solution & $67.9(\mathrm{n}=10,940)$ & $72.3(\mathrm{n}=293)$ \\
Basic Catch Your Breath & $81.4(\mathrm{n}=2,830)$ & $\mathrm{N} / \mathrm{A}$ \\
Basic Vital Signs & $85.4(\mathrm{n}=2,310)$ & $\mathrm{N} / \mathrm{A}$ \\
Basic Sense, Think, Move & $78.9(\mathrm{n}=4,151)$ & $70.2(\mathrm{n}=1,462)$ \\
Advanced Seeking the Sugar Solution & $\mathrm{N} / \mathrm{A}$ & $63.4(\mathrm{n}=1,178)$ \\
Advanced Where is Your DNA? & $\mathrm{N} / \mathrm{A}$ & $83.9(\mathrm{n}=457)$ \\
Advanced Catch Your Breath & N/A & $78.0(\mathrm{n}=226)$ \\
Advanced Vital Signs & N/A & $65.0(\mathrm{n}=1,165)$ \\
Advanced Sense, Think, Move & N/A & $71.0(\mathrm{n}=1,406)$ \\
Stop the Outbreak & N/A & $\mathbf{7 0 . 0}(\mathrm{n}=\mathbf{7 , 0 1 5})$ \\
Average (all modules) & $\mathbf{7 1 . 4}(\mathrm{n}=\mathbf{2 8 , 4 1 6})$ & \\
\hline
\end{tabular}

${ }^{1}$ Students in grade six are listed in either column depending on whether or not they attended an elementary school serving students in K-6 (second column) or a middle school (third column) 


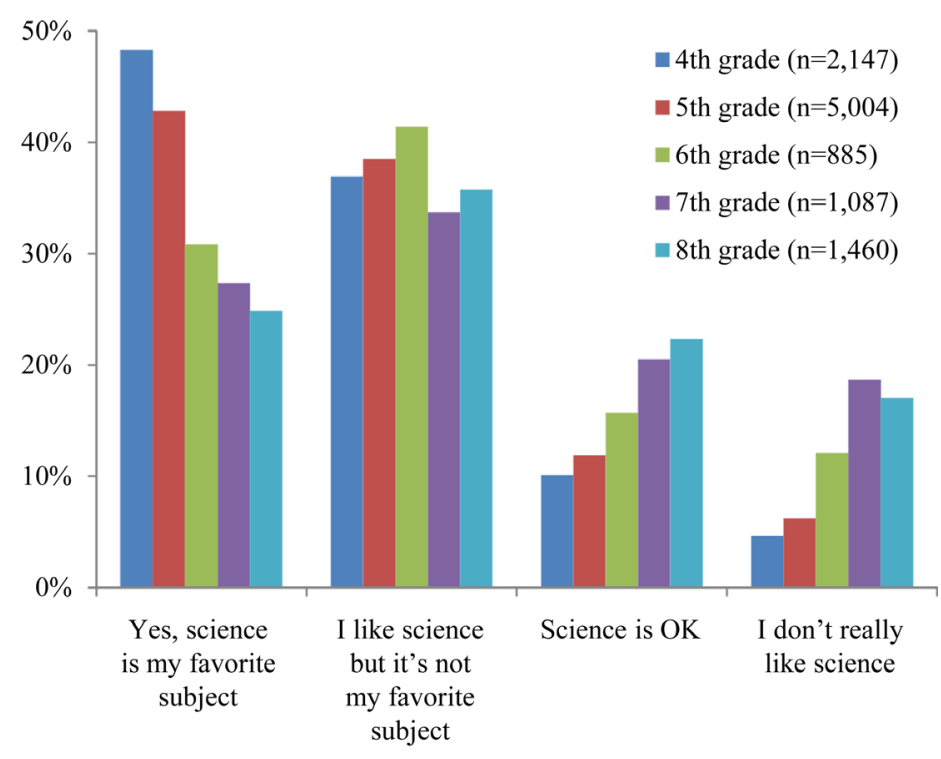

Figure 3. Student responses to a question about their perspective on learning science.

suggest that students successfully comprehended the material addressed in each of the modules. In reviewing the responses to the STEM-career interest question, it was noted that one third of students indicated that they had always wanted to pursue a STEM-related career, and that another third were considering it. Of interest is the fact that $14.2 \%$ of students selected the response suggesting that they had changed their mind as a result of their experience on the Science Adventure Lab. Given that more than 55,000 students have participated in the program, this represents a significant number of students $(7,887)$ who are considering a career in STEM when they might not have otherwise. We recognize that it is highly likely that the responses are influenced by the excitement of being onboard the mobile lab and doing a fun experiment, and acknowledge that these responses may not predict future career plans. Nevertheless, the data are encouraging and support the use of this type of outreach as a strategy to stimulate interest in careers in STEM. The data showing student interest in learning science are consistent with published literature showing a decline as students enter middle school. The objective is to provide experiences to students in elementary school that are powerful and engaging enough that they create a lasting impression that helps to ameliorate the decline in interest that occurs in the middle school years.

Strengths of the Approach. There are a number of advantages to using a mobile laboratory as a strategy for increasing the equity of access to high-quality science education and for stimulating interest in STEM careers. These include the ability to provide outreach across a large geographic area, to limit the burden on school resources, to allow students to use authentic laboratory and medical equipment, and to interact with scientists. The strengths of this approach are discussed in detail below:

- Improving access to science education. Opportunities for science enrichment such as field trips to museums, science centers, and academic institutions are concentrated in urban locations. A mobile laboratory allows students to participate in science enrichment activities and interact with scientists regardless of their geographic location and without leaving their school.

- Limited burden on school financial resources and schedule disruptions. Even when available, field trips require transportation, which can be a significant expense for schools. Even when available, field trips require transportation which can be a significant expense for schools. We are fortunate that our program is available to qualifying schools at no charge, which was reported to be a significant benefit by participating teachers and school administrators. Additionally, taking large numbers of students to an offsite location for a field trip disrupts the daily schedule. Classes onboard the mobile laboratory occurred during regularly-scheduled class times and without disrupting recess or lunch times.

- Access to authentic, research-grade and medical equipment in a laboratory setting with classes led by practicing scientists and education professionals. As mentioned above, students in elementary school are least likely to have access to hands-on laboratory experiences and equipment, or teachers may not have adequate training to fully utilize any scientific equipment or tools when they are available. The mobile lab brings the science and instructors into the elementary school.

- A supportive network of mobile laboratory programs around the US and internationally. Mobile labs first became popular in the US in the late 1990s (Jones and Stapleton, 2017). Many mobile lab programs, including the Science Adventure Lab, belong to the Mobile Laboratory Coalition (MLC), a non-profit organization of mobile and other laboratory-based education programs built on scientist and educator collaborations. The organization supports member programs as they provide equity of access to authentic, hands-on, inquiry-based contemporary science education for K-12 students, educators, and communities. The MLC continues to serve as a resource for new and emerging programs, and members willingly share curriculum that has been optimized for use on a mobile lab.

- Mobile labs can be created at a variety of price points, making them accessible to programs with a wide range of financial resources. One of the lowest cost options is retrofitting an existing vehicle; more expensive options include custom building a vehicle to meet specific program needs. A custom vehicle like the Science Adventure Lab costs approximately $\$ 750,000-\$ 850,000$ to build. Ongoing op- 
erating costs can vary widely. Program managers should budget $\$ 80,000-\$ 100,000$ annually for small equipment, consumables and other lab supplies, $\$ 8,000-\$ 10,000$ annually for fuel, licensing and vehicle taxes, and up to $\$ 10,000$ annually for maintenance, depending on the age of the vehicle. There are several staffing models used by mobile lab programs which can include volunteers, students, or paid employees. The associated costs vary depending on role, education and experience, and are defined by the organization's compensation model and resources.

Challenges. The data collected from students who participated in the program were effective in providing program staff with immediate feedback on comprehension so that the curriculum could be refined. Survey responses from teachers, anecdotal observations of program staff, and the many thousands of thank you letters received from students over the past eight years all suggest that the students had positive, meaningful experiences while onboard the Science Adventure Lab. Research indicates that even short interventions can have a significant impact on students' motivation and acquisition of skills as long as the intervention includes active engagement (Pellegrino and Hilton, 2012; Fitzakerley et al., 2013). However, there are a number of challenges associated with directly measuring the longer term impact of an outreach program like the Science Adventure Lab. These include:

- A single time point of data collection onboard the mobile lab with no opportunity for follow-up or pre- and post-visit assessments due to time constraints. We recognized that participating in the program could take time away from other instruction, so we attempted to minimize the time burden on teachers.

- Lack of ability to track students, since all data are collected anonymously. Each school selected which grade level participated. At some schools, students had multiple experiences in different grades, while others had only one experience. Since the data were anonymous, it is not possible to link student responses from year to year or correlate the number of experiences with any particular outcome.

- Lack of accessibility and parking for a large vehicle. Some schools in residential and urban areas were not able to participate due to lack of accessibility. Additionally, regardless of the location of the school, it is critical to plan the route to schools and consider the impact of factors such as low power lines, traffic circles, speed bumps, and bridges with low clearance.

- Module set up time. Setting up the equipment for each curriculum module each morning and stowing it safely at the end of the day is time consuming and adds to the length of the work day for program staff. The Science Adventure Lab carries the equipment and supplies needed for all of the curriculum modules, so, additional time must be built into the schedule to allow for the change between modules.
In summary, the Science Adventure Lab program has successfully enriched science education at low-resource schools by providing engaging, hands-on learning opportunities to diverse populations in both urban and rural locations. The program has contributed to improving the equity of access to STEM education and positive science experiences where schools might have limited local resources.

\section{AUTHOR INFORMATION Author Contributions}

The manuscript includes contributions from all listed authors. All authors have given approval to the final version of the manuscript.

\section{FUNDING SOURCES}

The Science Adventure Lab program was made possible by a founding gift from Purchase A Miracle, Washington state's premier grocery and drugstore campaign that raises funds for Seattle Children's. Operational support is provided by SCRI as well as the following corporations, foundations, and guilds: Mazda, Verizon, Microsoft, the Gary E. Milgard Foundation, Alaska Airlines Foundation, Norman Raab Foundation, Firland Foundation, and the SOVREN guild.

\section{ACKNOWLEDGEMENTS}

The authors would like to thank current and former members of the Science Education Department, as well as the faculty and staff at SCRI who help to make the Science Adventure Lab program possible. We also wish to thank all of the students and teachers who have helped make this program a success.

\section{ABBREVIATIONS}

STEM: Science, technology, engineering, and mathematics; NAEP: National Assessment of Educational Progress; SCRI: Seattle Children's Research Institute; OSPI: Office of Superintendent of Public Instruction; NCES: National Center for Education Statistics; ESD: Educational Service Districts; ADA: Americans with Disabilities Act; NGSS: Next Generation Science Standards

\section{REFERENCES}

Adams, C. (2015). Addressing disconnect between student skills and employer needs: Education Week. http://blogs.edweek.org/edweek/college_bound/2015/03/addressing mismatch_between_job_needs_and_education_system. html. 
Banilower, E. R., Weis, A. M., Campbell, K. M., Malzahn, K. A., Weiss, I. R., and Smith, P. S. (2013). Report of the 2012 National Survey of Science and Mathematics Education.

Bell, P., Lewenstein, B., Shouse, A. W., and Feder, M. A. (2009). Learning Science in Informal Environments: People, Places, and Pursuits. Washington, D.C National Academies Press.

Bybee, R. W., Taylor, J. A., Gardner, A., Van Scotter, P., Powell, J. C., Westbrook, A., and Landes, N. (2006). The BSCS 5E Instructional Model: Origins and Effectiveness. A Report Prepared for the Office of Science Education National Institutes of Health.

Chen, X., and Weko, T. (2009). Students Who Study Science, Technology, Engineering, and Mathematics (STEM) in Postsecondary Education: National Center for Education Statistics. http://nces.ed.gov/pubs2009/2009161.pdf.

Committee on STEM Education. (2013). Federal Science, Technology, Engineering, and Mathematics (STEM) Education 5-year Strategic Plan. Retrieved from http://www. whitehouse.gov/sites/whitehouse.gov/files/ostp/Federal STEM_Strategic_Plan.pdf.

Committee on Underrepresented Groups and the Expansion of the Science and Engineering Workforce Pipeline. (2011). Expanding Underrepresented Minority Participation: America's Science and Technology Talent at the Crossroads. In National Academies Press (Ed.). Washington, D.C. National Academy of Sciences.

Fitzakerley, J. L., Michlin, M. L., Paton, J., and Dubinsky, J. M. (2013). Neuroscientists' classroom visits positively impact student attitudes. PLoS One, 8(12). doi: https://doi. org/10.1371/journal.pone.0084035

Jones, A. L., and Stapleton, M. K. (2017). 1.2 million kids and counting-Mobile science laboratories drive student interest in STEM. PLoS Biol, 15(5), e2001692. doi: https://doi. org/10.1371/journal.pbio.2001692

Knox, K. L., Moynihan, J. A., and Markowitz, D. G. (2003). Evaluation of short-term impact of a high school summer science program on students' perceived knowledge and skills. Journal of Science Education and Technology, 12(4), 471478.

Lacey, T. A., and Wright, B. (2009). Occupational employment projections to 2018. Monthly Labor Review.

Lennon, C. (2014). Lack of skilled workers threatens economic growth. U.S. News \& World Report. https://www.usnews. com/news/stem-solutions/articles/2014/10/30/lack-ofskilled-workers-threatens-economic-growth-in-stemfields.

Markowitz, D. G. (2004). Evaluation of the long-term impact of a university high school summer science program on students' interest and perceived abilities in science. Journal of Science Education and Technology, 13(3), 395-407.

National Research Council. (2013). Next Generation Science Standards: For States, By States. Washington, D.C. The National Academies Press.

Pellegrino, J. W., and Hilton, M. L. (2012). Education for Life and Work: Developing Transferable Knowledge and Skills in the 21st Century. Washington, D.C. The National Academies Press.
Potvin, P., and Hasni, A. (2014). Analysis of the decline in interest towards school science and technology from grades 5 through 11. Journal of Science Education and Technology 23, 784-802. doi: https://doi.org/10.1007/s10956-0149512-X

Sivan, S., Leung, R., Woon, C., and Kember, D. (2000). An implementation of active learning and its effect on the quality of student learning. Innovations in Education \& Training International, 37(4), 381-389.

Swift, T. M., and Watkins, S. E. (2004). An engineering primer for outreach to K-4 education. Journal of STEM Education, 5 (3 and 4$), 67-76$.

Tai, R. H., Liu, C. Q., Maltese, A. V., and Fan, X. (2006). Career choice. Planning early for careers in science. Science, 312(5777), 1143-1144. doi: https://doi.org/10.1126/science. 1128690

U.S. Department of Education, Institute of Education Sciences, National Center for Education Statistics. (2016). National Assessment of Educational Progress (NAEP), 2015 Science Assessment.

United States Department of Agriculture Economic Research Service. (2018). State Facts Sheets. Retrieved from https:// www.ers.usda.gov/data-products/state-fact-sheets/ 